\title{
BTD Gene Mutations in Biotinidase Deficiency: Genotype-Phenotype Correlation
}

\author{
Ozlem Oz ${ }^{1}$, Meryem Karaca², Nurgul Atas ${ }^{3}$, Ataman Gonel ${ }^{4}$ and Mujgan Ercan ${ }^{4}$ \\ ${ }^{1}$ Department of Medical Genetics, Faculty of Medicine, Harran University Sanliurfa, Turkey \\ ${ }^{2}$ Department of Pediatrics, Division of Metabolism and Nutrition, Faculty of Medicine, Harran University Sanliurfa, Turkey \\ ${ }^{3}$ Department of Pediatrics, Faculty of Medicine, Harran University, Sanliurfa, Turkey \\ ${ }^{4}$ Department of Biochemistry, Faculty of Medicine, Harran University, Sanliurfa, Turkey
}

\begin{abstract}
Objective: To identify the biotinidase (BTD) gene mutations in patients with biotinidase deficiency in our region; and to determine the phenotype-genotype correlations in the presence of clinical findings.

Study Design: Descriptive study.

Place and Duration of Study: Department of Medical Genetics and Pediatric Metabolism Outpatient Clinic, Faculty of Medicine, Harran University, between January 2018 and June 2020.

Methodology: Two hundred and nine patients, who were found positive for biotinidase deficiency in heel blood screening, were included. Genomic DNA was isolated from peripheral blood. Next-generation DNA sequencing analysis was performed using primers covering the exon regions of the BTD gene. The results were analysed by the mutation surveyor programme.

Results: The most common mutation was $c .1330 \mathrm{G}>C$ (p.D444H) and the second most common mutation was c.470 G>A $(p . R 157 H)$. The majority of the mutations are missense; and they are especially located in the exon 4 . The most frequent mutations were found to be $D 444 \mathrm{H}$ and $R 157 \mathrm{H}$ with a rate of $66.66 \%$ in symptomatic patients.

Conclusion: Common mutations in BTD deficiencies were indentified. Associating them with phenotype-genotype data will assist clinicians in better genetic counselling and management in the future by implementing prevention programmes.
\end{abstract}

Key Words: Biotinidase deficiency, BTD gene, Newborn screening, Inherited metabolic disease, Newborn screening programme.

How to cite this article: Oz O, Karaca M, Atas N, Gonel A, Ercan M. BTD Gene Mutations in Biotinidase Deficiency: Genotype-Phenotype Correlation. J Coll Physicians Surg Pak 2021; 31(07):780-785.

\section{INTRODUCTION}

Biotinidase deficiency is an autosomal recessive metabolic disease characterised by neurocutaneous findings. ${ }^{1}$ Biotin is a water-soluble vitamin, a cofactor of carboxylase enzymes, involved in gluconeogenesis, fatty acid synthesis, and branched chain amino acid catabolism. Biotinidase is an enzyme involved in the biotin cycle and proteolytic degradation of biotin-dependent carboxylases. ${ }^{2}$ In biotinidase deficiency, there is a disruption in the separation of biotin, which cannot be released from biocide and biotinyl peptides, and endogenous biotin cannot rejoin the cycle. Therefore, dietary protein-bound biotin cannot be used. Biotin is excreted in the form of biocide in the urine and a progressive level of biotin deficiency develops gradually. ${ }^{3}$

Correspondence to: Dr. Ozlem Oz, Department of Medical Genetics, Faculty of Medicine, Harran University, Sanliurfa, Turkey

E-mail: ozlemdroz1@gmail.com

Received: March 16, 2021; Revised: May 31, 2021;

Accepted: June 21, 2021

DOI: https://doi.org/10.29271/jcpsp.2021.07.780
Biotinidase deficiency has been included in newborn screening programmes, which include phenylketonuria, congenital hypothyroidism and cystic fibrosis diseases in Turkey since 2008; and thus, increased the number of patients are being detected and treated. The incidence of disease is 1: 60.000 around the world, while the incidence is higher in Turkey with a 1:11.000 ratio. ${ }^{4}$ The disease is also diagnosed by biotinidase enzyme measurement with fluometric method and genetic mutation analysis with clinical suspicion. ${ }^{5}$ Biotinidase deficiency occurs as a result of mutations in the biotinidase (BTD) gene. The BTD gene is located in the 3q25.1 locus, consisting of four exons, and encoding 543 amino acids. It is expressed in lung, liver, skeletal muscle, kidney, pancreas, heart, brain and placenta in humans. ${ }^{6}$ To date, more than 150 different mutations have been identified in the BTD gene. ${ }^{7}$ The mutations that cause premature stop codon or cause aminoacid changes, such as deletion, insertion, cryptic adhesion formation mutation, single nucleotide insertion and point mutations cause the disease. $^{8}$

The neurologic and cutaneous symptoms of the condition include convulsions, hypotonia, alopecia, erythematous skin lesions, developmental retardation, conjunctivitis, and visual and hearing loss. If patients are treated after clinical manifesta- 
tions occur, findings such as hearing loss, optic atrophy, mental retardation; developmental retardation become evident, and it is not possible to improve the symptoms. If the disease is diagnosed and treated early, neurological findings would be prevented, and consequently morbidity and mortality can be significantly reduced. ${ }^{9}$

Because of common consanguineous marriages and high birth rates in Turkey, it is important to specify the different mutations defined in our country and other countries.

The aim of this study was to identify the BTD gene mutations in patients with biotinidase deficiency in Turkey; and to determine the phenotype-genotype correlation in the presence of clinical findings.

\section{METHODOLOGY}

This study was conducted at Department of Medical Genetics and Pediatric Metabolism Outpatient Clinic, Faculty of Medicine, Harran University, between January 2018 and June 2020 in order to identify the BTD gene mutations in patients and to determine the phenotype-genotype correlations in the presence of clinical findings. The results of the 209 patients' genetic analyses were investigated retrospectively. This study was conducted by considering ethical responsibilities according to the World Medical Association and the Declaration of Helsinki; and was approved by the independent Clinical Research Ethics Committee.

Patients who were found positive for BTD deficiency in heel blood screening in Medical Faculty Pediatric Metabolism Outpatient Clinic, were included in the study. Blood samples for the measurement of biotinidase activity included in the neonatal screening programme in Turkey were collected by the nurses with a heel stick and dropped on filter paper cards. Biotinidase activity (BA) from dried blood stains (DBS) was measured semiquantitatively with a fluorescence-based assay, using biotinyl-6-aminoquinoline as an artificial substrate (Trimaris fluorometric biotinidase kit). Biotinidase activity levels equal to or greater than 65 motion reference units (MRU) were considered normal, while those with values less than $65 \mathrm{MRU}$ were resent to repeat the measurement. In the repeated sample, patients with a BA value below $65 \mathrm{MRU}$ were referred to the pediatric nutrition and metabolism outpatient clinic. Biotinidase enzyme activity level was studied with the colorimetric method from the patients whose screening test results were suspicious. At least two consecutive blood samples, taken on different days, were used for BA measurement of the patients. After the blood was centrifuged at $1500 \mathrm{~g}$ for 10 minutes, the serum samples obtained were stored at $-80^{\circ} \mathrm{C}$ until analysis. Enzyme activity measurements were performed semi-quantitatively by the colorimetric method (FOCUS Neonatal Biotinidase Assay) and the highest result of the patient results was included in the study. In the experiment, biotinyl-p-aminobenzoic acid (BPABA) is used as the substrate for the reaction catalysed by biotinidase in serum and are products consisting of free biotin and $p$-aminobenzoic acid (PABA). At the end of the reaction, PABA is used to obtain an azo compound spectrophotometrically measured at $570 \mathrm{~nm}$ (Thermo Fisher Scientic). Enzyme activity is expressed as \% of average normal serum activity as released PABA. Low and high serum pools were used as quality control prior to each study. Results were determined by analysing after blank readings were taken.

For isolation of DNA from cases included in the study, 2 cc peripheral blood samples weretaken into tubes withEDTA (ethylene diamine tetra acetic acid). DNA extraction of the patients was isolated, according to the kit protocol using a commercial kit (high pure pcr template preparation kit, Roche, Germany) from peripheral blood samples. The concentration and purity measurement of the DNA samples was carried out with the commercial kit (Qubit dsDNA HS Assay Kit, USA). As a result of qubit measurement, DNAs were diluted with nuclease-free water to $10 \mathrm{ng} / \mu \mathrm{l}$. A library was created from the diluted DNA samples, using a commercial kit (IonAmpliseq Library Kit 2.0, USA). Consumables included in the commercial kit (AmpliSeq HiFi Mix, AmpliSeq Primer Pool, gDNA and nuclease-free Water) were used in the preparation of the PCR mix. Barcoding was done by the adapters (IonXpress Barcode Adapters) included in the kit. Amplification was performed with primer pairs containing exon regions of the BTD gene according to the kit protocol on PCR (NEXTflex ${ }^{T M}$ DNA Sequencing Kits, Bioo Scientific Corporation, Texas, United States). Next-generation DNA sequencing data was evaluated using Mutation Surveyor programme.

The ratio of all genes for one allele in this study group was determined to calculate allele frequency. The sum of the wild type (normal) allele and mutant allele was calculated, in all patients. The number of alleles was proportioned to the total number of alleles for calculating the frequency of each allele. Allele frequencies were calculated, according to the genotype structures of the patients and determined as percentages (\%).

\section{RESULTS}

Two hundred and nine patients, who were found to have low biotinidase enzyme activity in the neonatal screening programme and underwent genetic mutation analysis, were investigated retrospectively. One hundred and three (49.28\%) patients were males and $106(50.72 \%)$ were females. The authors observed that there were 20 different mutations when the BTD gene analysis results of patients with biotinidase deficiency were evaluated in the study population. The majority of the mutations were missense mutations; and it has been observed that they were especially located in the exon 4 . The most frequent mutation was c. $1330 \mathrm{G}>\mathrm{C}($ p.D444H) with a rate of $44.86 \%$, and the second most common mutation was $c .470$ $G>A(p . R 157 H)$ with a rate of $29.22 \%$ (Table l).

Socio-demographic information, age at diagnosis, status of consanguinity, ethnicity, biotinidase enzyme activity, genetic results of 24 patients with clinical findings were summarised in Table ll. 
Table I: Mutations causing biotinidase deficiency and their features.

\begin{tabular}{|c|c|c|c|c|c|}
\hline Nucleotide change & Protein change & Exon number & Allele number & Variant Type & Allele frequency (\%) \\
\hline c. $1330 \mathrm{G}>\mathrm{C}$ & p.D444H & 4 & 109 & Missense & 44.86 \\
\hline c. $470 \mathrm{G}>\mathrm{A}$ & p.R157H & 4 & 71 & Missense & 29.22 \\
\hline c. $557 \mathrm{G}>\mathrm{A}$ & p.C186y & 4 & 3 & Missense & 1.23 \\
\hline c.100_103delGGCT & p.G34Vfs*35 & 4 & 7 & Missense & 2.88 \\
\hline c. $38 \mathrm{G}>\mathrm{T}$ & p.C33F & 4 & 7 & Missense & 2.88 \\
\hline c.641 A>G & p.N214S & 4 & 1 & Missense & 0.41 \\
\hline C. $104 \mathrm{G}>\mathrm{C}$ & p.C35S & 4 & 7 & Missense & 2.88 \\
\hline C. $1253 \mathrm{G}>\mathrm{C}$ & p.C418S & 4 & 1 & Missense & 0.41 \\
\hline C.1361 A>G & p.Y454C & 4 & 2 & Missense & 0.82 \\
\hline c.1595 C>T & p.T532M & 4 & 1 & Missense & 0.41 \\
\hline C.1368 A>C & p.Q456H & 4 & 10 & Missense & 4.12 \\
\hline c. $171 \mathrm{~T}>\mathrm{G}$ & p.Y57* & 4 & 1 & Nonsense & 0.41 \\
\hline c.192_193insCATC & p.L69Hfs*24 & 4 & 2 & Frame-shift & 0.82 \\
\hline c.202_205dupATCC & p.Leu69Hisfs & 2 & 1 & Frameshift & 0.41 \\
\hline c. $235 \mathrm{C}>\mathrm{T}$ & p.R79C & 2 & 12 & Missense & 4.94 \\
\hline c.1324 delG & p.V442Sfs*59 & 4 & 1 & Frame-shift & 0.41 \\
\hline c. $1489 \mathrm{C}>\mathrm{T}$ & p.P497S & 4 & 2 & Missense & 0.82 \\
\hline c. $625 \mathrm{C}>\mathrm{T}$ & p.R209C & 4 & 2 & Missense & 0.82 \\
\hline c.959 T>G & p.F320C & 4 & 1 & Missense & 0.41 \\
\hline c. $98-104$ del7ins3 & p.C33Ffs*36 & 2 & 2 & Frame-shift & 0.82 \\
\hline
\end{tabular}

Eleven of the symptomatic patients had homozygous mutations, two had compound heterozygous, nine had heterozygous mutation, and two were normal. Although the results of genetic analysis were normal in two patients, enzyme activity was found to be partially low and have dermatological clinical findings. We observed that most of the patients with BTD mutations were asymptomatic $(88.52 \%)$ and the symptoms were observed only in $24(11.48 \%)$ patients. When symptomatic patients were evaluated, it was observed that most patients had dermatitis. In these patients, especially $p . D 444 H$ and $p . R 157 H$ mutations were found to accompany with dermatitis (Table II).

When the biotinidase enzyme activity was measured in patients whose neonatal screening test results were positive, enzyme activity was less than $10 \%$ in five $(2.39 \%)$ patients, enzyme activity was between $10 \%$ and $30 \%$ in 85 $(40.67 \%)$ patients. The rest of the patients had enzyme activity over $30 \%$. When the genetic results of the patients were evaluated, it was observed that $82(39.23 \%)$ patients have homozygous mutations, $42(20.1 \%)$ have compound heterozygous mutations, $68(32.54 \%)$ have mutations in a single allele, and 17 (8.13\%) have not any mutations in the BTD gene.

\section{DISCUSSION}

Biotinidase deficiency is divided into two categories as serious and partial deficiency, according to enzyme activity. Serious biotinidase deficiency is characterised by less than $10 \%$ serum enzyme activity, partial biotinidase deficiency is characterised by $10-30 \%$ serum enzyme activity. ${ }^{10}$ It has been reported that $Q 456 H, A 171 T, D 444 H, D 252 G$ mutations were common in the screening of the newborn in the United States by $52 \%$ of children with severe biotinidase deficiency. ${ }^{8}$ It was reported that the p.D444H was the most common mutation in Europe. ${ }^{11}$ Biotinidase deficiency is usually detected by newborn and family screening in Turkey. In a study involving a large number of patients with biotinidase deficiency, it was reported that p.R157H, p.D444H, c.98-104del7ins3, and p.T532M were common mutations in Turkey. ${ }^{12}$ In this study, the authors determined that the most common mutation was p.D444H with a rate of $44.86 \%$. Other common mutations were found to be $p \cdot R 157 H, R 79 \mathrm{C}$ and $Q 456 H$, respectively. In Turkey, Karaca et al. reported a different result from this study; they reported that $p . R 157 H$ mutation ratio was $32.2 \%$ in their study group. ${ }^{12}$ In this study, the authors did not find p.T196R, p.V199M, p.G310E, p.P368L, p.Y454C, R538C, p.D543H mutations or $100 \mathrm{G}>\mathrm{A} 3^{\prime}$ splice site mutations, which were previously reported another researches in Turkish patients. ${ }^{13-16}$

C418S mutation was identified for the first time in Hungary. It was first reported in Turkey in a patient with compound heterozygous mutation ( $D 444 \mathrm{H} / C 418 S$ ) by Karaca et al. It was observed that partial enzyme deficiency was accompanied by the patients with $C 418 S$ mutation. ${ }^{12,17}$ In this study, this mutation in a patient with heterozygous form and the enzyme activity was found to be $30 \%$. In addition, it was observed to cause frontal baldness clinically in the patient with C418S/D444H mutation. $D 444 H$ allele could alleviate the clinical manifestations by reducing the effect of the C418S mutation.

In biotinidase deficiency, symptoms may appear early or late, depending on the degree of enzyme deficiency, and may sometimes not be seen throughout the life. Those with a biotindase activity below zero or less than $1 \%$, constitute a very high risk group in terms of symptom development. In most of these patients, symptoms begin to appear from the first weeks of life, and sometimes life-threatening symptoms may occur. 


\begin{tabular}{|c|c|c|c|c|c|c|c|c|}
\hline $\begin{array}{l}\text { Patient } \\
\text { number }\end{array}$ & Sex & $\begin{array}{c}\text { Age at } \\
\text { diagnosis } \\
\text { (months+days) }\end{array}$ & Consanguinity & Ethnicity & Clinical findings & $\begin{array}{l}\text { Enzyme } \\
\text { activity } \\
(\%)\end{array}$ & Nucleotide change & $\begin{array}{l}\text { Protein } \\
\text { change }\end{array}$ \\
\hline 1 & M & $0+27$ & No & $\mathrm{T}$ & Diaper dermatitis & 32 & $\begin{array}{l}\text { Heterozygous } \\
\text { c.1368 A>C }\end{array}$ & p. Q456H \\
\hline 54 & $\mathrm{~F}$ & $0+21$ & Yes & $\mathrm{T}$ & Dry skin & 28 & Normal & - \\
\hline 57 & $M$ & $5+16$ & Yes & $T$ & Dermatitis & 2.8 & Homozygous c.1330 G>C & p. D444H \\
\hline 64 & $M$ & $0+20$ & No & $T$ & Hypotonia & 30 & Homozygous C.1330 G>C & p. D444H \\
\hline 70 & $\mathrm{M}$ & $6+17$ & No & $\mathrm{T}$ & Diaper dermatitis & 28 & Heterozygous c.470 G>A & p. R157H \\
\hline 81 & $\mathrm{~F}$ & $0+22$ & Yes & $T$ & Diaper dermatitis & 38 & Heterozygous c.470 G>A & p. R157H \\
\hline 88 & $\mathrm{~F}$ & $1+19$ & No & $\mathrm{T}$ & Alopecia & 22 & Homozygous c.1330 G>C & p. D444H \\
\hline 93 & M & $22+6$ & No & $\mathrm{T}$ & Dermatitis & 37 & $\begin{array}{l}\text { Homozygous } \\
\text { c. } 470 \mathrm{G}>\mathrm{A}\end{array}$ & p. R157H \\
\hline 99 & $\mathrm{M}$ & $10+0$ & Yes & $\mathrm{T}$ & Dermatitis & 20 & Heterozygous c.470 G>A & p. R157H \\
\hline 111 & $M$ & $1+4$ & No & $T$ & Dermatitis & 12 & Homozygous c.1368 A>C & p. Q456H \\
\hline 113 & M & $1+22$ & No & $\mathrm{T}$ & Dermatitis & 12 & Heterozygous c.235 C>T & p. R79C \\
\hline 117 & M & $23+27$ & No & $\mathrm{T}$ & $\begin{array}{l}\text { Hyperkeratosis on the } \\
\text { scalp }\end{array}$ & 16 & $\begin{array}{l}\text { Homozygous } \\
\text { c. } 470 \mathrm{G}>\mathrm{A}\end{array}$ & p. R157H \\
\hline 123 & M & $0+23$ & Yes & $T$ & Frontal baldness & 30 & Heterozygous C.1253 G>C & p. C418S \\
\hline 129 & M & $3+7$ & No & T & $\begin{array}{c}\text { Hyperemia of the skin, } \\
\text { Dermatitis }\end{array}$ & 44 & \begin{tabular}{|l|} 
Heterozygous c. $235 \mathrm{C}>\mathrm{T}$ \\
Heterozygous c. $470 \mathrm{G}>\mathrm{A}$
\end{tabular} & $\begin{array}{l}\text { p. R79C } \\
\text { p. R157H }\end{array}$ \\
\hline 136 & $M$ & $2+12$ & No & $\mathrm{T}$ & Dermatitis & 31 & Normal & - \\
\hline 140 & $\mathrm{~F}$ & $23+1$ & No & $\mathrm{T}$ & $\begin{array}{l}\text { Neurological } \\
\text { dysfunction }\end{array}$ & 45 & $\begin{array}{l}\text { Homozygous } \\
\text { c. } 470 \mathrm{G}>\mathrm{A}\end{array}$ & p. R157H \\
\hline 143 & $\mathrm{~F}$ & $2+19$ & No & $T$ & Dermatitis & 28 & Heterozygous c.470 G>A & p. R157H \\
\hline 155 & $\mathrm{~F}$ & $0+18$ & No & $\mathrm{T}$ & Dermatitis & 18 & Homozygous c.1330 G>C & p. D444H \\
\hline 157 & $\mathrm{~F}$ & $3+0$ & Yes & $\mathrm{s}$ & Seborrheic dermatit & 18 & Homozygous c.1330 G>C & p. D444H \\
\hline 158 & M & $0+22$ & Yes & $T$ & Difficulty in walking & 10 & Homozygous C.1330 G>C & p. D444H \\
\hline 160 & $\mathrm{~F}$ & $95+30$ & Yes & $\mathrm{T}$ & $\begin{array}{l}\text { Hyperkeratosis on the } \\
\text { scalp }\end{array}$ & 18 & Homozygous c.1330 G>C & p. D444H \\
\hline 171 & $\mathrm{~F}$ & $2+15$ & Yes & $\mathrm{T}$ & Dermatitis & 40 & $\begin{array}{c}\text { Heterozygous c.235 C>T } \\
\text { Heterozygous C.1330 G>C }\end{array}$ & $\begin{array}{l}\text { p. R79C } \\
\text { p. D444H }\end{array}$ \\
\hline 172 & M & $0+29$ & No & $T$ & Dermatitis & 25 & Heterozygous c.235 C>T & p. R79C \\
\hline 208 & $F$ & $2+3$ & No & $\mathrm{T}$ & Dermatitis & 35 & $\begin{array}{c}\text { Heterozygous } \\
\text { c.192_193ins CATC }\end{array}$ & p. L69Hfs*24 \\
\hline
\end{tabular}

People with enzyme activity between $1-10 \%$ also have the risk of being symptomatic. ${ }^{18}$ In some patients, only one symptom is occured; while in others, more than one neurological and skin manifestations can be observed. Skin symptoms in patients with biotinidase deficiency include erythematous rash, seborrheic dermatitis and partial/total alopecia. Symptoms in infancy include signs of nutritional difficulties, respiratory system such as tachypnea and apnea. In fact, if treatment is not initiated early in the patients, restlessness, lethargy and coma may develop and even result in death. ${ }^{19,20}$ In a study of 31 Turkish patients

In a study conducted in America, the most common mutation detected in children with symptomatic findings was reported to be c.98-104del7ins3 with a rate of $35 \%$. In the present study, the most frequent mutation was found to be $D 444 H$ and $R 157 H$ with a rate of $66.66 \%$ in symptomatic patients. Although the $\mathrm{D} 444 \mathrm{H}$ mutation has been reported as mostly asymptomatic in the literature, this mutation in the present study was found to be one of the most common variants, mostly in symptomatic patients. This suggests that this allele may change from a clinically asymptomatic to a symptomatic state, and this may be due to underlying stress and additional diseases. Therefore, it should be kept in mind with deep biotinidase deficiency and symptomatic by Pomponio et al., it was stated that 98G:del7ins3 mutation was common in patients with clinics in Turkish populations similar to the United States. ${ }^{14}$ In this study, it is noteworthy that this mutation was not observed in symptomatic patients. On the other hand, $R 79 \mathrm{C}$ mutation was reported to be seen common in Turkish pediatric patients detected by both clinical and newborn screening by Pomponio et al. ${ }^{14}$ In this study, it was observed that this mutation was the third most frequent mutation in patients with clinical findings.

that this mutation may cause changes in enzyme activity in the presence of underlying factors. $\mathrm{R} 157 \mathrm{H}$ mutation was reported with a slightly lower frequency $(27 \%)^{21}$ or as a rare mutation in several reports. ${ }^{13,22}$ In the present study, the R157H (29.22\%) was the second most common mutation.

Dermatological manifestations were observed most frequently among clinical findings in this study. The most common cutaneous findings were dermatitis, alopecia, dry skin, frontal baldness, hyperkeratosis. The mutation frequently accompanying dermatological findings was observed to be $p . R 157 H$ and $p . D 444 H$ mutations. In the 
study conducted by Canda et al., different from this study results, it was reported that dermatological findings were detected more rarely and that these individuals had homozygous $p . D 444 H$ mutation. ${ }^{23}$ On the other hand, when the authors evaluated the patients with clinical findings in the present study by origin, one patient with seborrheic dermatitis complaint was of Syrian origin and had homozygous p.D444H mutation with partial enzyme deficiency.

In this study, it was determined that only three patients diagnosed with neurological findings included walking difficulties, hypotonia and mental retardation findings. Homozygous p.D444H mutation was detected in two patients with hypotonia and walking difficulties, and one patient with mental retardation had homozygous $p . R 157 H$ mutation. In the study of Canda et al, neurological findings were reported to be observed with p.D444H mutation. ${ }^{23}$ Furthermore in the study of Karaca et al., only neurological findings were observed in symptomatic patients and these patients were reported to have mostly homozygous c.98-104del7ins3 mutation. ${ }^{12}$ In this study, this mutation was observed as heterozygous in only two patients, and the patients were asymptomatic. Furthermore, in this study, neurological findings were found less frequently than other studies. In 2008, together with the receipt of the newborn screening programme, biotinidase activity has increased the number of patients detected in Turkey. ${ }^{24}$ In this way, contrary to what is stated in other studies, neurological findings were found to be rare and dermatological findings were less mild in this study.

Consanguineous marriage is usually observed at a high rate in this region. Accordingly, the incidence of diseases with autosomal recessive inheritance is high in our society. In this study, children were mostly homozygous due to the increasing incidence of kinship in Middle Eastern countries as in the Jordan example. ${ }^{25}$ The parents of the patients of this study, with mutations, were tested for the carrier status and detailed information and genetic counselling were given about the risk of diseases in their next pregnancies.

\section{CONCLUSION}

As a result, the most common mutations in patients with biotinidase deficiency in our region were identified and the reflection of these mutations to the clinic was described in this study. In addition, it is thought that different clinical findings may occur in individuals with the same mutation and also, when the socio-economic status of the patients with the phenotype and genotype incompatibility was considered. It is necessary to be closely followed and informed by metabolic specialists and genetic counsellor.

\section{CONFLICT OF INTEREST:}

The authors declared no conflict of interest.

\section{AUTHORS' CONTRIBUTION:}

OO, MK, NA, AG, ME: Principal investigations, study conception and design, sample collection and molecular analysis, patient mangement and interpretation of clinic data.

All authors were involved in drafting the article and / or revising it critically for important intellectual content.

\section{REFERENCES}

1. Wolf B. Biotinidase: Its role in biotinidase deficiency and biotin metabolism. J Nutr Biochem 2005; 16(7):441-5. doi: 10.1016/j.jnutbio.2005.03.024.

2. Gravel RA, Narang MA. Molecular genetics of biotin metabolism: Old vitamin, new science. J Nutr Biochem 2005; 16(7):428-31. doi: 10.1016/j.jnutbio.2005.03.020.

3. Desai S, Ganesan K, Hegde A. Biotinidase deficiency: A reversible metabolic encephalopathy. Neuroimaging and MR spectroscopic findings in a series of four patients. Pediatr Radiol 2008; 38(8):848-56. doi: 10.1007/s00247008-0904-z.

4. Baykal T, Hüner G, Sarbat G, Demirkol M. Incidence of biotinidase deficiency in Turkish newborns. Acta Paediatr 1998; 87(10):1102-3. doi: 10.1080/080352598750031518.

5. Porta F, Pagliardini V, Celestino I, Pavanello E, Pagliardini S, Guardamagna $\mathrm{O}$, et al. Neonatal screening for biotinidase deficiency: A 30-year single center experience. Mol Genet Metab Rep 2017; 13:80-2. doi: 10.1016/j.ymgmr.2017. 08.005 .

6. Wolf B. Biotinidase deficiency: "If you have to have an inherited metabolic disease, this is the one to have". Genet Med 2012; 14(6):565-75. doi: 10.1038/gim.2011.6.

7. Procter M, Wolf $B$, Crockett DK, Mao R. The biotinidase gene variants registry: A paradigm public database. $G 3$ (Bethesda) 2013; 3(4):727-31. doi: 10.1534/g3.113. 005835.

8. Hymes J, Stanley CM, Wolf B. Mutations in BTD causing biotinidase deficiency. Hum Mutat 2001; 18(5):375-81. doi: 10.1002/humu.1208.

9. Wolf B. Biotinidase deficiency. GeneReviews ${ }^{\circledR}[$ Internet]: University of Washington, Seattle; 2016.

10. Wolf B. Biotinidase deficiency: new directions and practical concerns. Curr Treat Options Neurol 2003; 5(4):321-8. doi: 10.1007/s11940-003-0038-4.

11. Thodi G, Schulpis KH, Molou E, Georgiou V, Loukas YL, Dotsikas $Y$, et al. High incidence of partial biotinidase deficiency cases in newborns of Greek origin. Gene 2013; 524(2):361-2. doi: 10.1016/j.gene.2013.04.059.

12. Karaca M, Özgül RK, Ünal Ö, Yücel-Yılmaz D, Kılıç M, Hişmi $B$, et al. Detection of biotinidase gene mutations in Turkish patients ascertained by newborn and family screening. Eur J Pediatr 2015; 174(8):1077-84. doi: 10.1007/s00431015-2509-5.

13. MuÈhl A, MoĖslinger D, StoÈckler-Ipsiroglu S. Molecular 
characterisation of 34 patients with biotinidase deficiency ascertained by newborn screening and family investigation. Eur J Hum Genet 2001; 9(4):237-43. doi: 10.1038/sj. ejhg.5200620.

14. Pomponio R, Coskun T, Demirkol M, Tokatli A, Ozalp I, Hüner $\mathrm{G}$, et al. Novel mutations cause biotinidase deficiency in Turkish children. J Inherit Metab Dis 2000; 23(2):120-8. doi: 10.1023/a:1005609614443.

15. Sivri HSK, Genç GA, Tokatlı A, Dursun A, Coşkun T, Aydın Hi, et al. Hearing loss in biotinidase deficiency: Genotypephenotype correlation. J Pediatr 2007; 150(4):439-42. doi: 10.1016/j.jpeds.2007.01.036.

16. Wolf B, Jensen KP, Barshop B, Blitzer M, Carlson M, Goudie $\mathrm{DR}$, et al. Biotinidase deficiency: Novel mutations and their biochemical and clinical correlates. Hum Mutat 2005; 25(4):413. doi: 10.1002/humu.9329.

17. Laszlo A, Schuler E, Sallay E, Endreffy E, Somogyi C, Varkonyi A, et al. Neonatal screening for biotinidase deficiency in Hungary: Clinical, biochemical and molecular studies. J Inherit Metab Dis 2003; 26(7):693-8. doi: 10.1023/b:boli.0000005622.89660.59.

18. Koohmanaee S, Zarkesh M, Tabrizi M, Rad AH, Divshali S, Dalili S. Biotinidase deficiency in newborns as respiratory distress and tachypnea: A case report. Iranian J Child Neurolo 2015; 9(2):58.

19. Norrgard KJ, Pomponio RJ, Hymes J, Wolf B. Mutations causing profound biotinidase deficiency in children ascertained by newborn screening in the United States occur at different frequencies than in symptomatic children. Pediatr Res 1999; 46(1):20-7. doi: 10.1203/00006
450-199907 000-00004.

20. Hsu RH, Chien YH, Hwu WL, Chang IF, Ho HC, Chou SP, et al. Genotypic and phenotypic correlations of biotinidase deficiency in the Chinese population. Orphanet J Rare Dis 2019; 14(1):1-6. doi: 10.1186/s13023-018-0992-2.

21. Baykal T, Gokcay G, Gokdemir Y, Demir F, Seckin Y, Demirkol $M$, et al. Asymptomatic adults and older siblings with biotinidase deficiency ascertained by family studies of index cases. J Inherit Metab Dis 2005; 28(6):903-12. doi: 10.1007/s10545-005-0161-3.

22. Torkamandi S, Rezaei S, Mirfakhraie R, Golmohamadi S, Gholami M. The novel homozygous p. Asn197_Ser201del mutation in BTD gene is associated with profound biotinidase deficiency in an Iranian consanguineous family. Mol Biol Rep 2020; 47(5):4021-7. doi: 10.1007/s11033020-05424-4.

23. Canda E, Yazici H, Er E, Kose M, Basol G, Onay H, et al. Single center experience of biotinidase deficiency: 259 patients and six novel mutations. J Pediatr Endocrinol Metab 2018; 31(8):917-26. doi: 10.1515/jpem-2018-0148.

24. Tezel B, Dilli D, Bolat $H$, Şahman H, Özbaş S, Acıcan D, et al. The development and organization of newborn screening programs in Turkey. J Clinical Lab Anal 2014; 28(1):63-9. doi: 10.1002/jcla.21645.

25. Al-Eitan LN, Alqa'qa K, Amayreh W, Khasawneh R, Aljamal $\mathrm{H}$, Al-Abed $\mathrm{M}$, et al. Identification and characterization of BTD Gene mutations in jordanian children with biotinidase deficiency. J Pers Med 2020; 10(1):4. doi: 10.3390/jpm 1001.0004. 